\title{
Revue Revue de I'histoire des religions de I'histoire des religions

Théodore AGALLIANOS, Dialogue avec un moine contre les Latins (1442), édition critique, traduction et commentaire par Marie-Hélène BLANCHET

Paris, Publications de la Sorbonne («Byzantina Sorbonensia », 27), 2013, 251 p., $24 \mathrm{~cm}, 40 €$, ISBN 978-2-85944-732-8.

\section{Vincent Déroche}

\section{(2) OpenEdition \\ Journals}

Édition électronique

URL : http://journals.openedition.org/rhr/8283

DOI : $10.4000 /$ rhr.8283

ISSN : 2105-2573

Éditeur

Armand Colin

\section{Édition imprimée}

Date de publication : 1 octobre 2014

Pagination : 509-511

ISBN : 978-2-200-92912-1

ISSN : 0035-1423

\section{Référence électronique}

Vincent Déroche, "Théodore agallianos, Dialogue avec un moine contre les Latins (1442), édition critique, traduction et commentaire par Marie-Hélène BLANCHET », Revue de l'histoire des religions [En ligne], 3 | 2014, mis en ligne le 03 novembre 2014, consulté le 22 septembre 2020. URL : http:// journals.openedition.org/rhr/8283; DOI : https://doi.org/10.4000/rhr.8283

Ce document a été généré automatiquement le 22 septembre 2020

Tous droits réservés 


\section{Théodore AGALLIANOS, Dialogue avec} un moine contre les Latins (1442), édition critique, traduction et commentaire par Marie-Hélène

\section{BLANCHET}

Paris, Publications de la Sorbonne (« Byzantina Sorbonensia », 27), 2013, 251 p., $24 \mathrm{~cm}, 40 €$, ISBN 978-2-85944-732-8.

\section{Vincent Déroche}

\section{RÉFÉRENCE}

Théodore AgALlianos, Dialogue avec un moine contre les Latins (1442), édition critique, traduction et commentaire par Marie-Hélène BLANCHET, Paris, Publications de la Sorbonne (« Byzantina Sorbonensia », 27), 2013, 251 p., $24 \mathrm{~cm}, 40 €$, ISBN 978-2-85944-732-8.

1 Il est bien connu que l'Union des Églises élaborée au concile de Ferrare-Florence en 1438-1439 entre Byzantins et Occidentaux a échoué, parce que les Byzantins y étaient devenus majoritairement hostiles avant même la chute de Constantinople en 1453, et a fortiori ensuite, lorsque l'appui militaire occidental avait perdu tout intérêt. Mais l'échec de l'Union à Byzance n'était pas écrit d'avance, comme l'essentiel de l'historiographie tend à le dire un peu vite, et les tentatives de l'empereur et du patriarche d'imposer l'Union de force ont eu un certain succès. Tout l'intérêt du dialogue anti-unioniste de Théodore Agallianos est précisément d'être écrit en 1442, lorsque les jeux ne sont pas encore faits et que l'antilatinisme ultérieur ne s'est pas imposé. Hiéromnémon (chef du protocole ecclésiastique) du patriarcat, Agallianos est l'un des rares officiers patriarcaux à ne pas être allé au concile, pour cause de maladie : 
il n'a donc pas signé l'Union, ne s'est pas compromis, et s'y oppose dès le retour de la délégation byzantine en 1440 . Déposé de son office, il entame une campagne subversive dont ce texte est le premier jalon.

Le texte est peu connu jusqu'ici parce qu'il n'en reste qu'un seul manuscrit complet, le Mosquensis graecus 248 sans doute copié dans l'entourage d'Agallianos, une seule édition de 1705 en Valachie basée sur ce témoin, plus un fragment de manuscrit à l'Athos. La présente édition commentée rend bien compte de l'histoire du manuscrit et du texte donc de sa réception dans l'antilatinisme ultérieur - et analyse également l'enjeu de la forme littéraire choisie, le dialogue fictif, plus didactique et militant que polémique, habilement rédigé pour provoquer un effet de réel et esquisser fugitivement les quelques doutes des anti-unionistes pour mieux les dissiper. Le texte, contrairement aux pamphlets ultérieurs mieux connus, vise délibérément non pas un public lettré compétent en théologie, mais des simples comme le personnage du moine, ce qui permet d'appréhender les enjeux du débat pour une « piété populaire » et une identité collective au quotidien que les sources savantes décrivent souvent mal : c'est de ce fait un document anthropologique exceptionnel sur la religiosité byzantine. L'édition sur un seul manuscrit proche du temps de la rédaction posait assez peu de problèmes philologiques, mais ils sont traités correctement et le lecteur dispose d'un texte sûr, tout en bénéficiant d'une traduction très exacte et élégante, qui rend justice à la saveur «parlée » de l'original.

3 Le commentaire, très riche, explore les visées d'Agallianos: après une condamnation non tant de l'Union que des "uniates" orthodoxes avant la lettre, on passe à un discours général antilatin franchement xénophobe qui installe la polémique à un niveau anthropologique et identitaire plutôt que théologique. Le hiéromnémon Agallianos se mettant lui-même en scène - évoque brièvement, mais de façon presque unique, la persécution de l'Église unioniste officielle contre les dissidents comme lui. Ses intransigeances et ses indulgences sont souvent inattendues par rapport à l'image historiographique habituelle de l'antilatinisme : indulgence relative envers les évêques grecs envoyés à Florence (que d'autres sources accusent franchement de corruption) et envers l'empereur byzantin lui-même (mais en laissant entendre qu'il sait bien que l'Union est une erreur religieuse grave, mais s'y croit contraint par la nécessité politique), mention assez rapide de la résistance de Marc d'Éphèse qui a ensuite été le héros par excellence des anti-unionistes; intransigeance sur la gravité de la rupture (Agallianos considère qu'il y a déjà deux Églises, unioniste et anti-unioniste, à peine trois ans après Florence : c'est l'un des tout premiers témoignages) et sur l'impossibilité de s'entendre avec les Latins. D'une façon très originale, Agallianos « relit » dans ce but la prise de Constantinople par les Croisés en 1204 (qu'il présente comme un complot délibéré des Latins, déjà irrémédiablement hostiles) et surtout l'Union de Lyon de 1274, qui est pour lui l'occasion d'évoquer sur le mode hagiographique la résistance du moine Mélétios, et en parallèle la damnation de l'empereur Michel VIII (paradoxalement, la conservation des deux dépouilles sert à prouver la sainteté de l'un et la damnation de l'autre - pour Michel VIII une dépouille gonflée, il est vrai, où s'esquisse l'image ultérieure du vampire). Agallianos témoigne là d'une véritable procédure de canonisation à Byzance à la fin du xIII ${ }^{e}$ siècle, et implicitement fait en retour un procès en délégitimation à la dynastie Paléologue. Une longue diatribe contre les Latins « démontre » que leur doctrine de la procession de l'Esprit empêche qu'il y ait chez eux un vrai sacré et de la vraie sainteté, avec des arguments au niveau des pratiques 
populaires et de l'hagiographie: les reliques byzantines emportées par les Latins y perdent toute efficacité miraculeuse, les moines latins même vertueux n'ont pas de sainteté - le climax étant un portrait de François d'Assise en amant de Claire, peut-être en partie emprunté à une polémique dominicaine, mais révélateur de la diffusion (attestée par ailleurs) d'un début de culte de François chez les orthodoxes qu'il fallait combattre. En effet, le commentaire montre bien que souvent Agallianos répond sans l'avouer à des doutes des orthodoxes que l'on sent en creux : hésitation à qualifier d'autres chrétiens (les Latins) comme impies, popularité naissante des franciscains, attachement à la dynastie impériale, etc. Le dialogue atteste ici presque involontairement l'étendue des influences du monde latin sur Byzance. Par sa lecture des signes divins et par sa théorie de la sainteté, Agallianos permet d'esquisser une identité orthodoxe qui s'affirme en s'opposant à Rome et surtout aux pratiques occidentales. En somme, la présente étude restitue parfaitement le mérite majeur de l'œuvre: de faible intérêt du point de vue intellectuel, elle donne en revanche un aperçu vivant de l'ambiance d'une période fugace, avant le basculement de l'opinion publique.

\section{AUTEURS}

\section{VINCENT DÉROCHE}

Centre national de la recherche scientifique (Laboratoire Orient et Méditerranée). 